\title{
Plano de Desenvolvimento da Escola (PDE-Escola): ferramenta de autonomia escolar?
}

\author{
Elisangela Maria Pereira Schimonek \\ Doutoranda em Educação pela Universidade Estadual de Campinas, Campinas, SP - Brasil. \\ elisangela@educacao.rc.sp.gov.br
}

Maria Aparecida Segatto Muranaka Departamento de Educação do Instituto de Biociências da Universidade Estadual Paulista, Rio Claro, SP - Brasil. ma.segatto@hotmail.com

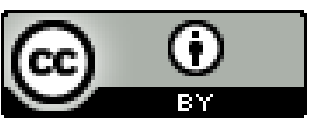

Educação: teoria e prática, Rio Claro, SP, Brasil - elSSN: 1981-8106

Está licenciada sob Licença Creative Common

\section{Resumo}

O presente ensaio analisa a implantação do Plano de Desenvolvimento da Escola (PDEEscola) em duas unidades educacionais do município de Limeira-SP, as quais apresentaram o Ideb/2007 abaixo da média nacional e foram direcionadas a adotar o programa a partir de 2009. O PDE-Escola é um programa do Governo Federal que se proclama capaz de viabilizar a autonomia da escola, a obtenção de melhores resultados educacionais e a modernização da estrutura, organização e gestão escolares por meio de modelos administrativos gerenciais. Este estudo qualitativo teve por finalidade verificar se os objetivos delineados por tal programa, no que tange à garantia da autonomia escolar, ganham concretude na prática. A metodologia utilizada foi o estudo de caso, com base na coleta de dados (entrevistas e questionários semiestruturados, análise documental e revisão bibliográfica). Os resultados obtidos acenaram para a imposição de um sistema padronizado e burocrático, pautado por mecanismos de monitoramento, cobrança e controle que dificultaram a conquista gradativa da autonomia pedagógica, administrativa e financeira das escolas pesquisadas.

Palavras-chave: PDE-Escola. Autonomia Escolar. Gestão Escolar.

\section{School Development Plan (PDE-School): a toll for school autonomy?}

\section{Abstract}

This essay analyses the implementation of the School Development Plan (PDE-School) in two educational units in Limeira, SP, who presented the Ideb/2007 below the national average 
and were directed to adopt the program starting in 2009. The PDE-School is a program of the Federal Government which proclaims itself capable of enabling the school autonomy, better educational outcomes and the modernization of the school structure, organization and management by means of administrative managerial models. The purpose of this qualitative study was to ascertain whether the objectives outlined for this program, with respect to the guarantee of school autonomy, gain concreteness in practice. The methodology used was case studies based on data collection (semi-structured interviews and questionnaires, documentary analysis and literature review). The results indicated the imposition of a standardized and bureaucratic system, based on mechanisms of monitoring, request and control that hindered the gradual conquest of pedagogic, administrative and financial autonomy of the schools surveyed.

Keywords: PDE-School. School Autonomy. School Management.

\section{Introdução}

Influenciadas pelo ideário neoliberal, por prescrições de organismos internacionais, como o Banco Mundial, e, ainda, por princípios da reforma do Estado brasileiro, empreendida no governo de Fernando Henrique Cardoso (FHC), as políticas educacionais dos anos 1990 foram vias de materialização de modelos e atributos gerenciais na educação (SCHIMONEK, 2012).

A gestão das instituições educacionais ganhou centralidade e, em nome da autonomia escolar, foi induzida a adotar metodologias de planejamento estratégico, cujas metas são a racionalização e a eficácia dos resultados educacionais.

À luz desses princípios gerenciais, o Plano de Desenvolvimento da Escola foi concebido, no referido governo, sob a égide do Fundo de Fortalecimento da Escola (Fundescola), oriundo de um acordo internacional entre o Banco Mundial e o Ministério da Educação (MEC), e interferiu incisivamente na gestão das escolas públicas. Tal ferramenta gerencial de planejamento estratégico proclamou-se capaz de viabilizar a organização e a autonomia escolares, a gestão democrática e a melhoria do desempenho dos alunos, sendo prescrita a elaboração coletiva de um plano estratégico para subsidiar suas ações.

No governo de Luiz Inácio Lula da Silva, o Plano de Desenvolvimento da Escola foi incorporado ao Plano de Desenvolvimento da Educação (PDE/2007), tomando como públicoalvo as escolas que apresentaram um Índice de Desenvolvimento da Educação Básica (Ideb) abaixo da média nacional.

O foco do programa foi posto na melhoria dos resultados educacionais, que, ao serem medidos por meio de uma combinação entre a Prova Brasil e indicadores de 
desempenho dos alunos coletados pelo Censo Escolar, serviram à responsabilização/ culpabilização dos profissionais da educação.

$\mathrm{Na}$ tentativa de constatar se a autonomia escolar ganha concretude com a implantação do PDE-Escola, propomos, neste ensaio, a análise dos dados empíricos obtidos em duas escolas da rede municipal de Limeira que, por apresentarem o Ideb 2007 abaixo da média nacional (4.2), foram direcionadas a implantar o Programa a partir de 2009.

Preliminarmente, abordamos o contexto histórico-político em que o PDE-Escola foi concebido e a reconfiguração pela qual passou no governo Lula, para, por fim, analisarmos a autonomia escolar frente à ferramenta em questão.

\section{A Reforma do Aparelho do Estado e da Educação nos anos 90}

A ofensiva neoliberal disseminou a ideia de que o Estado, por ser ineficiente e incapaz de promover o controle fiscal, era o grande causador das crises que o capitalismo vinha sofrendo nas últimas décadas. Ao mesmo tempo, propagou-se o princípio de que o mercado e a iniciativa privada podiam garantir mais qualidade, eficiência, produtividade e equidade, defendendo-se sua superioridade em relação à atuação estatal. (SCHIMONEK, 2012, p. 80).

Com base nesse diagnóstico, no governo FHC (1995-2002) assumiu-se que a crise pela qual o Brasil passava decorria do fato de o Estado ter se desviado de suas funções básicas para ampliar sua presença no setor produtivo, o que teria gerado a gradual deterioração dos serviços públicos e o agravamento da crise fiscal e inflacionária (BRASIL, 1995).

Assim, a reforma do aparelho estatal foi apontada como um mecanismo necessário para assegurar uma maior estabilidade social e o crescimento sustentado da economia, redefinindo o papel do Estado:

\footnotetext{
Mudar o Estado significa, antes de tudo, abandonar visões do passado de um Estado assistencialista e paternalista, de um Estado que, por força de circunstâncias, concentrava-se em larga medida na ação direta para a produção de bens e serviços. Hoje, todos sabemos que a produção de bens e serviços pode e deve ser transferida à sociedade, à iniciativa privada, com grande eficiência e com menor custo para o consumidor (CARDOSO, 1998, p. 15).
} 
O ministro Luiz Carlos Bresser Pereira, ao ser nomeado para o recém-criado Ministério da Administração Federal e Reforma do Estado (MARE), baseou-se no diagnóstico de que o Estado se encontrava em crise para ressaltar que a reforma era uma exigência dos processos de globalização e da necessidade de se estabelecerem mecanismos para a superação do desequilíbrio. Em vista disso, elaborou o Plano Diretor da Reforma do Aparelho do Estado (PDRAE):

A reforma do Estado deve ser entendida dentro do contexto de redefinição do papel do Estado, que deixa de ser o responsável direto pelo desenvolvimento econômico e social pela via da produção de bens e serviços para fortalecer-se na função de promotor e regulador desse desenvolvimento (BRASIL, 1995).

O Estado, então, assumiu o papel de formulador, regulador e avaliador das políticas públicas, reduzindo sua atuação como executor e prestador de serviços, função delegada aos estados e municípios sob o discurso da descentralização. Com a proposta de um Estado mínimo quanto ao provimento dos serviços sociais, e máximo quanto à garantia dos interesses do capital, diminuiu-se a participação estatal na economia e incentivaram-se a livre competição do mercado, a racionalização dos gastos públicos e a privatização dos serviços à população.

O PDRAE realizou uma crítica à forma de administração pública burocrática e determinou sua substituição por um modelo gerencial, fundamentado em conceitos de eficiência, qualidade e produtividade do serviço público, voltados ao atendimento do cidadão-cliente. Pautado por princípios neoliberais, propôs a flexibilização da estabilidade dos servidores, permitindo demissões; o enxugamento dos quadros de pessoal; a reforma na previdência; o fim da obrigatoriedade do regime jurídico único; a meritocracia (promoção na carreira em função do bom desempenho profissional e da aprovação em cursos específicos); a implantação de sistemáticas de avaliação por meio da elaboração de indicadores de desempenho; a competição administrativa no interior do Estado; a descentralização dos serviços públicos, cabendo aos estados e municípios a execução das políticas públicas; a consolidação de modelos gerenciais para o setor público, objetivando gerar melhores resultados; e o controle social como garantia da qualidade dos serviços públicos (BRASIL,1995).

As políticas educacionais dos anos 1990, em sintonia com os princípios que permearam a reforma do Estado brasileiro, também foram fortemente influenciadas pelo 
ideário neoliberal e por ditames de organismos internacionais. A prioridade de atendimento recaiu sobre o Ensino Fundamental, e a gestão educacional passou a se orientar por modelos gerenciais com ênfase na racionalização de gastos e na implantação de sistemáticas de avaliação de desempenho como formas de controlar os resultados.

Constatamos que algumas políticas adotadas nesse período revestiam-se de caráter compensatório, visando corrigir as desigualdades sociais. Uma dessas políticas foi o Fundescola ${ }^{1}$, um programa do MEC cofinanciado pelo Banco Mundial (BM) e elaborado em parceria com as secretarias de educação. Iniciado em junho de 1998, com o fim de direcionar recursos para as regiões mais pobres do Norte, Nordeste e Centro-Oeste, integrava doze ações, sendo o Plano de Desenvolvimento da Escola (PDE) o seu carro-chefe, uma vez que sinalizava grande destaque na escola com foco no aluno.

\begin{abstract}
Nesse processo, a escola é tida como responsável pela melhoria da qualidade de ensino e o projeto visa a modernizar a gestão e fortalecer a autonomia da escola, segundo um processo de planejamento estratégico coordenado pela liderança da escola e elaborado de maneira participativa. A busca do apoio público ao desenvolvimento centrado na escola é um ingrediente essencial para assegurar o clima político e os recursos para a sustentação e a expansão do processo de desenvolvimento da educação (OLIVEIRA; FONSECA; TOSCHI, 2005, p. 132).
\end{abstract}

O PDE ${ }^{2}$ objetivava fortalecer e aperfeiçoar a gestão da escola pública, além de garantir a qualidade de ensino com base na elaboração coletiva de um plano estratégico. Para a construção desse planejamento, a equipe escolar realizava um levantamento de dados para diagnosticar a situação educacional, o que viabilizava a identificação dos valores, a visão de futuro e a missão da escola. Eram traçados objetivos, estratégias e planos de ações a serem alcançados a curto, médio e longo prazo.

De acordo com Oliveira, Fonseca e Toschi (2005, p. 141), alguns gestores enfatizavam que o modelo de gestão do $\mathrm{BM}$, por meio do $\mathrm{PDE}$, era muito diretivo e não levava à autonomia da escola, uma vez que, para sua execução, se fixavam exigências que o tornavam altamente burocrático. Com essa sobrecarga de atividades burocráticas, a demanda de atividades processuais aumentava, sem que isso necessariamente contribuísse para o trabalho em sala de aula.

\footnotetext{
${ }^{1}$ Criado através do acordo 17402-BR entre o Brasil e o Banco Mundial.

${ }^{2}$ Refere-se ao Plano de Desenvolvimento da Escola, que, no governo Lula é denominado PDE-Escola. O formato do programa (concepções, objetivos, ações e estratégias) é o mesmo em ambos os governos (FHC e Lula), ocorrendo apenas pequenos ajustes.
} 
O PDE previa sistemáticas de controle ${ }^{3}$ sobre os planos das escolas, com manuais para o acompanhamento e planejamento de ações, além de regras para a utilização de recursos e prestação de contas quanto ao dinheiro repassado à instituição, direcionado à aquisição de materiais e à melhoria do espaço escolar.

Assim, em uma mesma escola, dois projetos com concepções divergentes eram construídos pela equipe escolar: de um lado, o Projeto Político Pedagógico (PPP), teoricamente de caráter mais democrático, elaborado a partir dos saberes dos próprios atores da instituição escolar e pautado por valores que levavam em conta as especificidades locais e as aspirações da comunidade educativa por uma escola mais autônoma e de qualidade; e de outro, o PDE, mais burocrático e diretivo, fundamentado no controle da gestão e do trabalho dos profissionais da educação, com uma visão gerencial, moderna e estratégica, focada na racionalização dos gastos e na eficiência operacional.

\section{Plano de Desenvolvimento da Educação e o PDE-Escola}

Em 2007, no governo Lula, o MEC lançou o Plano de Desenvolvimento da Educação (PDE), cuja intenção proclamada era a de reduzir a desigualdade de oportunidades educacionais (BRASIL, 2007, p. 6). Concebido como um plano articulado para a educação, centrava-se na Educação Básica, mas também trouxe ações para o Ensino Superior.

Apesar dos elogios por priorizar o ensino de qualidade, o PDE foi alvo de muitas críticas por constituir não um plano de fato, e sim um programa de metas que desconsiderava o Plano Nacional de Educação (PNE) em vigência, bem como a participação da sociedade civil em sua elaboração, privilegiando o grupo Compromisso Todos Pela Educação, constituído por empresários que trouxeram à educação uma gestão gerencial.

O Ideb ficou estabelecido como um dos eixos centrais do PDE, pois por meio dele foi possível buscar uma articulação entre a União, os estados e os municípios em prol da melhoria dos resultados de avaliações institucionais, cabendo ao MEC oferecer apoio técnico e financeiro àqueles que apresentassem desempenho aquém do esperado.

Além disso, o governo Lula deu continuidade a algumas políticas educacionais implantadas pelo governo FHC. Uma delas é o PDE-Escola, que foi incorporado ao PDE com melhoria apenas em sua abrangência, ampliada a todas as regiões brasileiras.

\footnotetext{
${ }^{3} \mathrm{O}$ controle era exercido por técnicos das secretarias de educação e equipe gestora das escolas. 
O PDE-Escola objetiva levar qualidade de ensino às escolas públicas cujo Ideb tenha ficado abaixo da média nacional. Como no governo FHC, observamos a ênfase posta nas avaliações de desempenho, na publicidade dos resultados, no estabelecimento de ranking entre as escolas e na culpabilização dos envolvidos no processo pedagógico pelos índices alcançados.

O MEC define o PDE-Escola como uma ferramenta gerencial de planejamento estratégico, que busca elevar o desempenho dos alunos e da escola ao melhorar a organização escolar e viabilizar a gestão democrática, a autonomia e o fortalecimento da gestão pedagógica. O Programa favorece a integração da equipe escolar, que detecta e analisa as principais dificuldades de seu cotidiano e, então, elabora o Plano de Suporte Estratégico (PSE), com foco na aprendizagem dos alunos. Além disso, é desenvolvido pela equipe da escola o Plano de Ações Financiáveis (PAF), que contempla ações que requeiram a aplicação de recursos financeiros. Tais recursos são disponibilizados pelo Programa Dinheiro Direto na Escola (PDDE). Segundo o MEC:

O PDE-Escola é uma ação de melhoria da gestão escolar fundamentada centralmente na participação da comunidade. No PDE-Escola, a comunidade escolar é diretamente envolvida em um plano de autoavaliação, que diagnostica os pontos frágeis da escola e, com base nesse diagnóstico, traça um plano estratégico. (BRASIL, 2007, p. 25).

Embora se proclame capaz de fortalecer a autonomia escolar, o PDE-Escola é alvo de críticas $^{4}$ por ser um instrumento burocrático, que compreende a escola de uma perspectiva empresarial, e por possuir um cunho de monitoramento e um viés tecnicista que se contrapõe à concepção de PPP enquanto identidade coletiva da escola.

\section{PDE-Escola e a Autonomia Escolar}

Etimologicamente, a palavra autonomia, do grego, indica a ideia de autogoverno, de governar-se a si próprio. Sua composição resulta da junção de dois termos: autos, que significa "por si mesmo", e nómos, que significa "lei". Logo, autonomia refere-se a um governo com leis próprias (GADOTTI; ROMÃO, 2004).

Foi no Manifesto dos Pioneiros da Educação Nova, de 1932, que a ideia de autonomia começou a ser construída no campo da educação, com algumas poucas alusões ao termo -

\footnotetext{
${ }^{4}$ Cf. Oliveira; Fonseca; Toschi (2005). 
fato que, contudo, não nos permite destituir o documento do mérito da inovação. $O$ que permeou o Manifesto foram os anseios por uma organização educacional baseada no princípio da autonomia e na ideia de autogoverno. Após esse período e anteriormente à década de 1980, raras foram as menções ao conceito nas legislações do ensino.

O significado de autonomia tem sido reconfigurado de acordo com o contexto histórico, social, econômico e político em vigência, gerando perspectivas distintas e controvérsias, entre as quais destacamos as das décadas de 1980 e 1990.

Na década de 1980, em cujo cenário despontava a possibilidade de vivências mais democráticas, as discussões em torno do termo autonomia foram retomadas. Gadotti e Romão (2004, p. 44) afirmam que o tema "autonomia da escola" encontrou suporte na Constituição Federal de 1988, que instituiu a "democracia participativa", criando instrumentos para o povo exercer o poder "diretamente" (Art. 1ํ). No que tange à educação, a Constituição de 1988 estabeleceu como princípios básicos o "pluralismo de ideias e de concepções pedagógicas" e a "gestão democrática do ensino público" (Art. 206), os quais podem ser considerados como fundamentos constitucionais da autonomia escolar.

Em consonância com a efervescência dos movimentos democráticos, a rearticulação dos movimentos sociais e a luta pela democracia, as propostas de alterações na gestão da escola pública apoiavam-se, principalmente, na defesa da administração coletiva da escola, na eleição de dirigentes escolares, na participação da comunidade usuária na definição dos objetivos da instituição, da constituição de instâncias coletivas de trabalho docente e na exclusividade do poder público sobre o financiamento da escola pública. Buscava-se instalar mecanismos de gestão pautados pela organização democrática dos diferentes setores que compunham a comunidade escolar, e, além disso, reivindicava-se maior autonomia para a escola no tocante à utilização de recursos descentralizados, com a consequente descentralização do poder de decisão (ADRIÃO, 2006, p. 57-58).

Nesse período histórico, houve grande empenho das escolas na implantação de mecanismos de participação de docentes, demais funcionários, pais e alunos nos processos decisórios, por meio de conselhos escolares, assembleias, grêmios estudantis e associação de pais e mestres.

Apesar de o termo em questão ter ganhado sentido mais claro nessa época, Martins (2001, p. 99) mostra que, por via de regra, ele vem sendo utilizado pragmaticamente desde 1980, às vezes como sinônimo de descentralização e desconcentração, outras vezes como 
referência à etapa subsequente de processos descentralizadores, a partir dos quais a unidade escolar estaria finalmente livre para elaborar seu próprio plano de voo.

O fato é que, mesmo com todas as reivindicações dos educadores em prol da conquista da autonomia financeira, pedagógica e administrativa das escolas, a autonomia escolar não ganhou concretude por meio das políticas educacionais concebidas na década de 80. Aliás, as políticas implantadas no período foram esvaziadas de conteúdos acerca da autonomia.

\begin{abstract}
O início da década de 1990 trouxe alterações no conteúdo e gestão das políticas educacionais e, por conseguinte, nos discursos que as justificam. Num contexto de derrota eleitoral dos partidos e propostas de governos ligados aos movimentos populares e sindicais, o debate em torno da gestão da educação e da escola adquire conteúdos gerenciais. Nestes, a ênfase numa necessária reestruturação institucional das unidades escolares e dos órgãos gestores da educação pública assume a forma do aumento da "responsabilização" das próprias escolas frente ao fracasso do sistema educacional público. (ADRIÃO, 2006, p. 62).
\end{abstract}

A organização do sistema educacional, no período, partiu do entendimento de descentralização como desresponsabilização do Estado quanto aos investimentos no ensino, com a transferência das responsabilidades pela execução de tarefas para o âmbito da escola. Ao mesmo tempo, porém, a concepção das políticas e o controle do poder decisório se mantiveram centralizados (SCHIMONEK, 2012, p. 167).

Martins (2001, p. 31) afirma que, para garantir a eficácia do sistema educacional, o Estado exercia controle sobre os processos descentralizadores de gestão do ensino, enquanto as escolas, tendo em vista sua autonomia, deviam se responsabilizar pelo sucesso e pelo fracasso do ensinar e aprender.

A política hegemônica dessa década guiou-se pela descentralização de parcos recursos destinados às unidades escolares, cuja autonomia se concretizava na função de gerenciá-los; pela padronização das metas a serem alcançadas; e pela centralização e controle dos resultados educacionais.

O termo autonomia, trazido à luz nesse contexto histórico e incorporado ao Plano de Desenvolvimento da Escola, concebido no período, diverge do conceito que adotamos:

O conceito de autonomia está etimologicamente ligado à ideia de autogoverno, isto é, à faculdade que os indivíduos (ou as organizações) têm de se regerem por regras próprias. Contudo, se a autonomia pressupõe a liberdade (e capacidade) de decidir, ela não se confunde com a "independência". A autonomia é um conceito relacional (somos sempre autônomos de alguém ou alguma coisa), pelo que a ação 
se exerce sempre num contexto de interdependência e num sistema de relações. A autonomia é também um conceito que exprime sempre um certo grau de relatividade: somos mais ou menos autônomos; podemos ser autônomos em relação a umas coisas e não ser em relação a outras. A autonomia é, por isso, uma maneira de gerir, orientar as diversas dependências em que os indivíduos e os grupos se encontram no seu meio biológico ou social, de acordo com as suas próprias leis (BARROSO, 2003, p. 16).

A autonomia escolar é a possibilidade de a escola agir e decidir dentro dos limites que a caracterizam como instituição pública não independente, considerando que se trata não de um organismo isolado, e sim de um organismo inserido em um contexto maior da sociedade, influenciado por fatores sociopolíticos e econômicos, integrado a um sistema educacional e sujeito a determinações legais e hierárquicas, as quais, na maioria das vezes, são definidas centralmente. Com isso, evidenciamos o caráter restrito da autonomia escolar, mas também ressaltamos a possibilidade de avanços gradativos por meio da articulação dos vários atores que compõem as unidades escolares, no sentido de estabelecer espaços de discussão e construção coletiva do PPP, reivindicar maiores recursos financeiros e definir regras que contemplem os anseios da comunidade escolar.

A atual Lei de Diretrizes e Bases da Educação Nacional (LDBEN), em seu Art. 15, determina que "os sistemas de ensino assegurarão às unidades escolares públicas de educação básica que os integram progressivos graus de autonomia pedagógica e administrativa e de gestão financeira, observadas as normas gerais de direito financeiro público" (BRASIL, 1996).

O fato de a autonomia da escola estar prevista nas atuais legislações do ensino não é garantia de sua efetivação na prática, de modo que é preciso concentrar esforços nessa direção. Ademais, do ponto de vista institucional, autonomia é diferente de anomia, pois uma escola autônoma não é soberana em suas decisões, visto que sofre determinações legais e cumpre regras concebidas por órgãos externos a ela.

Considerando que os atuais discursos e legislações enfatizam a necessidade de garantir a autonomia das unidades educacionais e que o PDE-Escola é apresentado como um mecanismo para fortalecer a autonomia, o que é dito se efetiva com a implantação de tal plano? 
Para elucidarmos essa questão de pesquisa, recorremos aos dados empíricos coletados em duas unidades escolares (escolas A e B) do município de Limeira - localizado no interior do estado de São Paulo - as quais implantaram o PDE-Escola a partir de 2009.

A escola A, que em 2011 ministrou a Educação Infantil e o Ensino Fundamental (do 1을 ao $4^{\circ}$ ano e $4^{-\underline{a}}$ série) a um total de 423 alunos, apresentou um Ideb/2007 de 3.8, ou seja, abaixo da média nacional (4.2); e, em 2009, quando implantou o PDE-Escola, superou essa média, atingindo um índice de 5.0. A escola B, em 2011, ofereceu os mesmos níveis de ensino da escola A, tendo 330 alunos matriculados, um Ideb/2007 de 4.0 e um Ideb/2009, pós PDE-Escola, de $6.3^{5}$.

Ao longo da aplicação das entrevistas, ficou evidente que nem os técnicos da Secretaria Municipal da Educação (SME) e muito menos os integrantes das equipes escolares foram consultados sobre a adesão ao PDE-Escola. Isso denota que, a partir da assinatura do Compromisso Todos pela Educação, os estados, o Distrito Federal e os municípios passaram a receber apoio técnico e financeiro do MEC, mas ficaram vulneráveis às determinações de diretrizes federais.

Eu particularmente tenho em pensamento que o PDE-Escola foi um tanto quanto imposto. Não foi assim: vamos tentar e ter tempo para analisar. Isso envolve uma série de implicações, é uma verba que você não pode perder. Como [...] explicar se perder? Ao mesmo tempo, isso gera contrapartidas [...]. Então é algo que eu não senti tempo para poder pensar se era interessante ou não (TÉCNICO DA SME).

Não, eu não fui consultado. Tomei conhecimento quando cheguei à escola. Foi meio que imposto, por conta da nota do Ideb que a gente alcançou. Então, esse foi o critério e a escola foi selecionada por conta dele; então fomos obrigados a aderir ao projeto, ao plano (DIRETOR DA ESCOLA A).

Questionamos os técnicos da SME a respeito de como ocorreu a implantação do PDE-

Escola no município de Limeira:

Primeiro nós tivemos uma formação em São Paulo, e as escolas, através da Direção, passaram pela formação. A gente tinha um cronograma de ações para fazer na unidade escolar. Havia também reuniões que fazíamos aqui na Secretaria para acompanhamento lá, e depois eram executadas as etapas do PDE-Escola. Nós conferíamos as etapas, as escolas refaziam e voltava para nós, e nós observávamos: estando de acordo, a gente validava como comitê local ${ }^{6}$ de acompanhamento e

\footnotetext{
${ }^{5}$ Os entrevistados entendem que o resultado do Ideb/2009 não é reflexo do PDE-Escola, mas é fruto do compromisso coletivo assumido pelos educadores em prol da melhoria da aprendizagem dos alunos.

${ }^{6}$ Uma prescrição do programa é a instituição de um Comitê Estratégico da SME para atuar junto às unidades escolares na elaboração, acompanhamento e avaliação do PDE-Escola.
} 
encaminhávamos para o MEC, que, por sua vez, às vezes acatava, às vezes devolvia para aprimoramento (TÉCNICO DA SME).

Esse depoimento explicita o controle e monitoramento que os técnicos das secretarias exercem na efetivação das etapas do PDE-Escola e, ainda, indica a dificuldade relacionada à validação do PSE/PAF pelo Sistema Integrado de Monitoramento, Execução e Controle (SIMEC), pois recorrente é o ir e vir desses planos até sua aprovação final.

Ao ser indagado se o PDE-Escola permitiu maior autonomia às unidades educacionais, um dos entrevistados assumiu o seguinte posicionamento:

Eu tenho umas reflexões sobre autonomia e acho difícil, porque, por exemplo, na medida em que a gente tem uma dificuldade enorme com o MEC em relação a prazos e datas, porque as coisas chegam num certo tempo, [em] que você não tem muito como agir de maneira correta, é atropelado [...]. Teria que respeitar o tempo da escola, considerar as necessidades plausíveis, mas há um conjunto de leis, regras, orientações, determinações [...]. Como não temos autonomia em relação ao prazo [...], não conseguimos fazer como gostaríamos [...] e, às vezes, fazendo atropelado, você comete erros [...]. Nesse sentido, eu acho que a autonomia precisaria ser repensada, e falando da experiência nossa, mas que sem dúvida acontece na escola também; [...] a escola tem que ter determinadas prioridades. Quando a gente fez a formação, havia as prioridades, que eram inclusão digital, acessibilidade [...], eram elementos pré-definidos. Nesse sentido, não havia uma autonomia (TÉCNICO DA SME).

Como se menciona na entrevista, ao elaborar o PSE/PAF, o MEC direciona algumas prioridades. Com relação aos critérios de eficácia escolar, as escolas são induzidas a concentrar esforços no processo de ensino-aprendizagem e nos resultados. Quanto ao critério da infraestrutura, precisam contemplar o Programa Escola Acessível e o Proinfo (instalação de laboratórios de informática), ainda que não haja problemas nesses quesitos. Destacamos o registro de uma ata de reunião do Comitê Estratégico com as escolas A e B:

[...] Ressaltou-se a importância do registro em ata de todas as reuniões do PDEEscola, bem como o envio de fotocópias dos documentos preenchidos ao Comitê Estratégico. Foram colocadas observações reiterando a necessidade de atender aos critérios de eficácia, contemplar o Proinfo e Acessibilidade. As diretoras das escolas colocaram que, apesar de o Programa colocar como necessária a inclusão dos Programas Proinfo e Acessibilidade, as mesmas sentem que não necessitam desses Programas (COMITÊ, 2009).

Ao considerarmos tal registro, constatamos que, além do monitoramento in loco pelo comitê, o acompanhamento da efetivação das etapas do PDE-Escola também ocorre por meio das reuniões realizadas no âmbito escolar. 
Retomando o último depoimento, percebemos, também, que o tempo do MEC não é o mesmo da escola. Para a elaboração de um plano dessa magnitude, seria necessário um tempo razoável para a escola refletir acerca de suas dificuldades e propor novas ações para a melhoria da qualidade do ensino, envolvendo toda a comunidade escolar. No entanto, o MEC determina e engessa os prazos para a inserção dos planos no SIMEC, o que inviabiliza a autonomia e a participação dos diferentes atores do processo educacional.

O professor coordenador da escola A aborda a autonomia escolar frente ao PDEEscola:

Então é assim uma autonomia entre aspas; [...] a escola foi escolhida também entre
aspas, [...] ganhou um bote salva-vidas porque estava afundando com a nota [...]. É
assim, autonomia? Está com as dificuldades assim, tal, mas [...] qual é a meta? A
meta é melhorar o Ideb. Então, assim, autonomia tem e não tem, no meu ponto de
vista. Tem de um lado porque, assim, nós tivemos oportunidades de conversar,
discutir, falar algumas coisas que a gente achava importantes, e não tem porque
tudo tem que ser voltado para melhorar o Ideb. Então, assim, só o fato de vir
aquele manual [...], por dizer, complicadíssimo, cheio de coisa... Nem sei se é tão
necessário tudo aquilo, [...] é muito minucioso, poderia ser mais prático
(PROFESSOR COORDENADOR).

O depoimento desse profissional reforça que a autonomia proclamada pelo PDEEscola é cerceada por imposições e cobranças quanto à melhoria do Ideb, além de destacar a metodologia pormenorizada e burocrática. Portanto, ao mesmo tempo que se coloca como um instrumento que favorece a autonomia da escola, possibilitando-lhe conceber e gerenciar seus processos, o PDE-Escola, contraditoriamente, impõe uma metodologia minuciosa de planejamento estratégico gerada por órgãos centrais, atribuindo à unidade escolar a execução de suas etapas e o cumprimento das prescrições.

Ressaltamos, ainda, que tal depoimento evidenciou como aspecto relevante do PDEEscola a possibilidade de a equipe escolar reunir-se para discutir suas dificuldades e possibilidades. Alguns entrevistados, quando indagados a respeito da autonomia escolar permitida pela implantação do programa, discorreram somente sobre a autonomia financeira. Destacamos dois depoimentos:

Não sei dizer para você se houve mais autonomia; teve, assim, para a compra de material, para investir no que realmente precisava, mas, por outro lado, a gente sabe que o PDE-Escola está vinculado ao PDDE; então, é uma autonomia relativa. [...] Quando vem o PDDE, as coisas vêm ligadas, [...] o PDE também vem vinculado, mas a verba foi um pouco maior e isso ajudou. Então, a autonomia foi um pouquinho maior por esse motivo, mas, assim, totalmente uma autonomia financeira, eu acredito que não (VICE-DIRETOR DA ESCOLA A). 
Ah, na minha opinião, sim, garantiu autonomia [...], porque assim nós recebemos mais verbas, vieram mais materiais pedagógicos e nós conseguimos desenvolver um trabalho melhor, porque nós até então tínhamos materiais, mas assim... não era muito, era pouco, então vieram mais coisas, [...] computadores... Então, dá para fazer um trabalho melhor (PROFESSOR DA ESCOLA B).

Ao abordarem a autonomia financeira, ficou claro que os recursos descentralizados ${ }^{7}$ foram importantes para a implantação das ações financiáveis, mas não suficientes para garantir a autonomia escolar. De certa forma, a ingerência metodológica do PDE-Escola limitou a aplicação desses recursos segundo as necessidades da escola.

Outro fato interessante é a associação da autonomia apenas à questão financeira, ignorando-se que o conceito, trazido sob a égide do PDE-Escola, é muito mais amplo, voltado à autonomia pedagógica, financeira e administrativa. Trata-se da materialização de uma tendência economicista, gerencialista, de controle, produtividade e responsabilização dos profissionais da educação pelos resultados que são controlados centralmente.

Solicitamos aos entrevistados que conceituassem a expressão autonomia escolar. Eis um depoimento:

É uma escola que pode seguir seu caminho, ter as suas metas, andar e fazer, sem ter que aceitar toda determinação sem questionar. A criança precisa de tal coisa, precisa de aulas diferenciadas, ou precisa seguir um outro tipo de metodologia que não é a convencional; o professor pode fazer isso sem correr o risco de ser punido pela Secretaria. [...] Não sei se a escola está preparada para ser autônoma, eu acho que só poderia dizer isso se a gente tivesse a oportunidade de ser uma vez. [...] Autonomia não é eu fazer o que quero, [...] e cada um fazer o que quer; seguimos regras, mas a escola tem que ter uma identidade (VICE-DIRETOR DA ESCOLA A).

Autonomia não é soberania, e muito menos anomia. Concordamos com o depoimento que evidencia a restrita autonomia em âmbito escolar, já que, ao fazerem parte de um sistema, as escolas seguem regras, legislações e diretrizes. No entanto, temos a conviç̧ão de que não devem adotar apenas uma postura de cumprimento das regulamentações. É necessário que avancem nos processos de participação e decisões compartilhadas, investindo na construção coletiva do PPP e na consolidação de uma gestão democrática para, gradativamente, se transformarem em instituições autônomas.

\footnotetext{
${ }^{7}$ As escolas A e B receberam duas parcelas de 13 mil reais (9.100 reais para custeio e 3.900 reais para capital) para a implantação das ações financiáveis.
} 
Também pedimos aos entrevistados que tecessem considerações sobre as mudanças ocorridas nas escolas com a implantação do programa. Eis algumas colocações:

\begin{abstract}
Eu penso que uma mudança importante é que as pessoas foram levadas a pensar na escola como um todo e integrada, e algumas passaram a ter uma visão mais abrangente, a perceber que uma atitude inicial [...] gera uma outra consequência. Ampliou a visão de planejamento, viabilizou o envolvimento das pessoas para planejar as ações. Aumentou a preocupação em melhorar a aprendizagem das crianças, o que reflete na melhoria do Ideb (TÉCNICO DA SME).

O CEMEP ${ }^{8}$, que é o órgão que fiscaliza os professores, vinha com relatório ou todo o planejamento de aula. Hoje em dia, semana passada, veio aqui e assistiu o HTPC, quer dizer, é uma cobrança: "Olha, nós estamos olhando você". O secretário que chega e fala para a diretora: "Oh, você tem que dar um jeito"... Foi uma cobrança mais efetiva... (PROFESSOR DA ESCOLA A).
\end{abstract}

Observa-se que o PDE-Escola propiciou uma visão sistêmica e a oportunidade de articulação e integração da equipe escolar em prol de um mesmo objetivo, além de apontar o papel da instituição escolar e a responsabilidade dos profissionais que nela atuam em relação à melhoria da aprendizagem dos alunos. No entanto, destacam-se o controle e a cobrança trazidos por essa metodologia.

Um aspecto interessante é que, quando retomamos os PSE/PAF das escolas envolvidas, observamos que não contemplam ações acerca da autonomia escolar, mas apontam uma enorme preocupação com relação à melhoria dos resultados obtidos nas avaliações internas e externas e quanto ao estabelecimento de mecanismos de monitoramento de desempenho. Além disso, verifica-se que as equipes escolares dedicam certa atenção à integração da comunidade com a escola; no entanto, nota-se, pelas estratégias e metas elencadas, uma fragilidade no que se entende por participação, concebida como a mera presença em eventos ou reuniões de pais. Não existem ações efetivas para o fortalecimento dos órgãos colegiados ou para a participação nos processos decisórios e na construção do PPP das escolas. Ainda, discorre-se sobre a necessidade de formação continuada dos profissionais de educação, mas isso não ocorreu por serem insuficientes os recursos distribuídos às escolas por via do PAF, os quais não foram complementados pelo município.

Apesar de o PDE-Escola se declarar capaz de garantir a autonomia escolar, as metas e estratégias descritas nos planos das escolas não foram suficientes para tal. Nesse sentido, a autonomia escolar proporcionada pelo Programa refere-se apenas à possibilidade de a

\footnotetext{
${ }^{8}$ Centro Municipal de Estudos Pedagógicos.
} 
comunidade escolar preencher as planilhas de seus planos e aplicar os recursos descentralizados direcionados pelo MEC.

\section{Considerações Finais}

Com base nos depoimentos dos entrevistados e na análise documental, evidenciouse que a garantia da autonomia escolar, propagada pelo PDE-Escola, é limitada pelo direcionamento das ações propostas pelo MEC (indução de escolhas), cabendo à escola apenas executá-las. Também foram notados a excessiva cobrança, o controle e a responsabilização exercidos por órgãos superiores no tocante à efetivação das metas do PSE/PAF, objetivando o monitoramento dos resultados educacionais de cada unidade escolar e a prévia vinculação dos recursos descentralizados a serem aplicados nas ações financiáveis.

\section{Referências}

ADRIÃO, T. Educação e produtividade: a reforma do ensino paulista e a desobrigação do Estado. São Paulo: Xamã, 2006.

BARROSO, J. O reforço da autonomia das escolas e a flexibilização da gestão escolar em Portugal. In: FERREIRA, N. S. C. (Org.). Gestão democrática da educação: atuais tendências, novos desafios. São Paulo: Editora Cortez, 2003.

BRASIL. Ministério da Educação. O Plano de Desenvolvimento da Educação: razões, princípios e programas. Brasília, DF, 2007.

Como elaborar o Plano de Desenvolvimento da Escola. 3. ed. Brasília:

Fundescola/Dipro/FNDE/MEC, 2006. Disponível em:

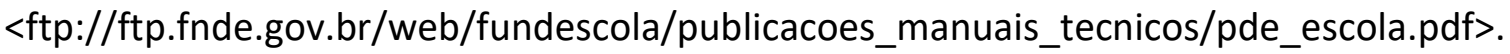
Acesso em: 18 jan. 2009.

. Lei nํ⒐394, de 20/12/1996. Lei de Diretrizes e Bases da Educação Nacional. Diário

Oficial da República Federativa do Brasil, Brasília, DF, 1996.

Ministério da Administração e Reforma do Estado. Plano Diretor da Reforma do Aparelho do Estado. Brasília, DF, 1995. 
Congresso Nacional. Constituição da República Federativa do Brasil. Brasília, DF, 1988.CARDOSO. F. H. Reforma do Estado. In: Pereira, L. C. B.; SPINK, P. (Orgs.). Reforma do Estado e administração pública gerencial. Rio de Janeiro: Fundação Getúlio Vargas Editora, 1998. p. 15-19.

GADOTTI, M.; ROMÃO, J. E. Escola cidadã - a hora da sociedade. In: GADOTTI, M.; ROMÃO I. E. (Orgs.). Autonomia da escola: princípios e propostas. São Paulo: Cortez, 2004. p. 43-50.

MARTINS, A. M. Autonomia e gestão da escola pública: entre a teoria e a prática. 2001. 306f. Tese (Doutorado em Educação) - Universidade Estadual de Campinas. Campinas, 2001.

OLIVEIRA, J. F. de; FONSECA, M.; TOSCHI, M. S. O programa Fundescola: concepções, objetivos, componentes e abrangência - a perspectiva de melhoria da gestão do sistema e das escolas públicas. Educação \& Sociedade, Campinas, v. 26, n. 90, p. 127-147, jan/ abr. 2005. Disponível em: <http://www.cedes.unicamp.br>. Acesso em: 6 jul. 2010.

SCHIMONEK, E. M. P. O Plano de Desenvolvimento da Escola (PDE-Escola): instrumento de autonomia para as unidades escolares? 2012. 278f. Dissertação (Mestrado em Educação) Universidade Estadual Paulista. Rio Claro, 2012. 